\title{
Comparison of plaque removal efficacy of new and 3-month-old toothbrushes in children
}

\author{
B. Malekafzali, ${ }^{1}$ M. Biria, ${ }^{1}$ N. Tadayon ${ }^{2}$ and H. Abbasi ${ }^{3}$
}

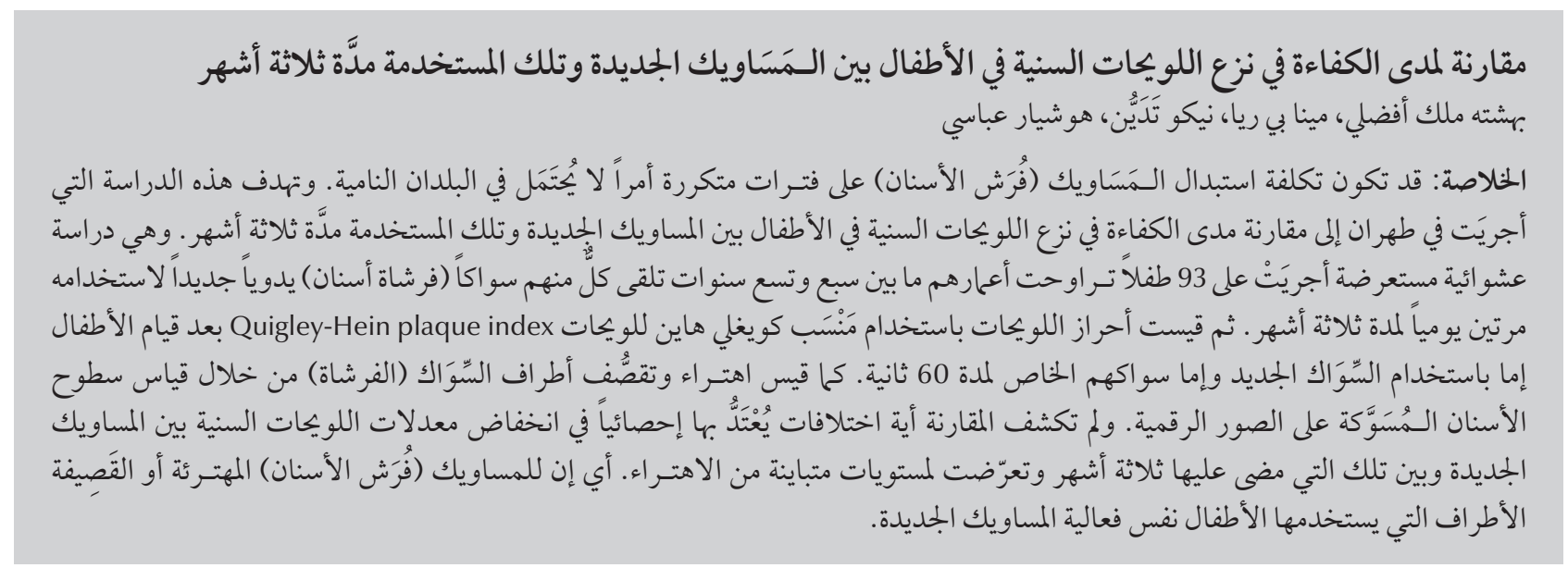

ABSTRACT The cost of replacing toothbrushes at frequent intervals may be prohibitive in underdeveloped countries. The objective of this study in Tehran was to compare the plaque removal efficacy of new and 3-monthold toothbrushes in children. In a randomized, crossover study, 93 children aged 7-9 years old received a new manual toothbrush to use twice per day for 3 months. Plaque scores were measured using the modified QuigleyHein plaque index after children had brushed for 60 seconds with either a new or their used toothbrush. Bristle wear of worn brushes was assessed by measuring brushing surface areas on digital images. Compared with new brushes in the same subjects, no statistically significant differences were found for plaque score reductions for 3-month-old toothbrushes exhibiting various degrees of wear. Worn toothbrushes are equally effective as new ones for children.

\section{Comparaison de l'efficacité des brosses à dents neuves et des brosses à dents utilisées depuis trois mois pour l'élimination de la plaque dentaire chez l'enfant}

RÉSUMÉ Le coût de remplacement des brosses à dents à intervalles rapprochés peut être prohibitif dans les pays en développement. L'objectif de la présente étude, conduite à Téhéran, était de comparer l'efficacité des brosses à dents neuves et des brosses à dents utilisées depuis trois mois pour l'élimination de la plaque dentaire chez l'enfant. Dans une étude randomisée croisée, 93 enfants âgés de sept à neuf ans ont reçu une nouvelle brosse à dents manuelle à utiliser deux fois par jour pendant trois mois. Les scores de plaque dentaire ont été mesurés à l'aide de l'indice de plaque de Quigley-Hein modifié, après un brossage de 60 secondes par l'enfant, soit avec une brosse à dents neuve, soit avec une brosse à dents usagée. L'usure des brosses à dents utilisées depuis trois mois a été évaluée en mesurant la superficie des zones brossées au moyen d'images numérisées. Aucune différence statistiquement significative n'a été observée entre les brosses à dents utilisées depuis trois mois ayant des degrés d'usure variés et les brosses à dents neuves, pour la réduction des scores de plaque dentaire chez les mêmes enfants. Les brosses à dents utilisées depuis trois mois ont donc une efficacité équivalente aux brosses à dents neuves chez l'enfant. 


\section{Introduction}

Good oral hygiene is essential for preventing dental caries and gingivitis and it is well acknowledged that effective daily removal of plaque biofilm plays a central role in maintaining oral health $[1,2]$. Of all the oral hygiene methods available, mechanical plaque removal with a manual toothbrush remains the primary method of maintaining good oral hygiene and the most affordable method for the majority of the population $[3,4]$.

The American Dental Association continues to emphasize the need for replacing toothbrushes every 3 to 4 months in order to optimize plaque removal [5]. Children's toothbrushes often need to be replaced more frequently. However, given that replacing toothbrushes frequently may be prohibitively expensive in underdeveloped countries, an evaluation of its real importance deserves attention. Typically, both in vitro [6] and in vivo studies in adults [7] have been conducted to examine the proposed superiority of a new toothbrush. While some authors found a reduced capacity of worn toothbrushes $[6,7]$, others reported that there was no significant difference between new and worn toothbrushes [8-10]. However, studies involving adults may not be directly applicable to children as children's poorer manual dexterity may result in a different pattern and rate of bristle wear. Only 1 study to date has examined the effects of toothbrush wear on plaque removal efficiency in children [11]. This crossover trial found no significant differences between new and 14-month-old toothbrushes with regard to plaque removal capacity. Since the toothbrushes were heavily worn, the grading of toothbrush wear was not performed in that study.

Given the inconclusive evidence about the relationship between toothbrush wear and plaque removal, especially in children, the primary goal of this study in the Islamic Republic of Iran was to investigate whether 3-month-old toothbrushes are as effective as new ones in terms of plaque removal in children. Other analyses included the assessment of the relationship between toothbrush wear and plaque removal efficiency.

\section{Methods}

\section{Study population}

Thissingle-blinded, randomized, crossover trial was conducted over a 3-month period between August and October 2009. The protocol was approved by the ethics review committee of Shahid Beheshti University of Medical Sciences, and written informed consent was obtained from parents prior to the commencement of the study. All the parents accepted for their children to participate in the study.

The sample size for this study was based on a previous comparative toothbrush study [11]. We randomly selected 3 primary schools in Tehran and 93 7-9-year-old children were recruited. For inclusion, subjects were required to have all central permanent incisors, upper lateral permanent incisors and all permanent first molars. These teeth had to be caries-free and without restorations on the facial, lingual/palatal or proximal surfaces. Participants were excluded if they were wearing oral prostheses, orthodontic brackets or appliances. Other reasons for exclusion included any physical limitations that might compromise normal tooth brushing technique, and evidence of neglected oral hygiene.

\section{Study protocol}

Each child was issued with a new toothbrush (Clinic Junior, Jordan) and given instructions on correct cleaning technique. They were instructed to use the allocated toothbrush exclusively for the next 3 months, twice per day. The toothbrush specifications were as follows: length, $128 \mathrm{~mm}$; 9 rows of bristles; 27 tufts; mean 24 [standard deviation
(SD) 1] monofilaments per tuft; height of monofilaments $=10 \mathrm{~mm}$; and diameter of filaments $=0.3 \mathrm{~mm}$.

At the end of the 3-month period, the used toothbrushes were returned in containers to prevent accidental distortion of the bristles during transport. Children were referred for 2 plaque assessment visits. They were asked to refrain from all oral hygiene procedures for $48 \mathrm{~h}$ and from eating, drinking and chewing gum for $4 \mathrm{~h}$ prior to each study visit. Following the measurement of the pre-brushing plaque scores at each visit, children were randomly allocated either a new toothbrush or their own used toothbrush. A measured amount of toothpaste (Crest Cavity Protection, Procter \& Gamble) was then placed on the toothbrush from a monojet syringe and children were instructed to brush without a mirror for $60 \mathrm{~s}$. After completion of brushing, the children rinsed with $20 \mathrm{~mL}$ of water for $20 \mathrm{~s}$ and a post-brushing plaque examination was performed.

Subjects used their usual method of oral hygiene for a brief washout period ( 2 weeks). At the second plaque assessment visit, identical procedures were followed, except that the toothbrush allocation was reversed.

\section{Plaque scoring}

Subjects swished with disclosing tablets (Eviplac, Biodinamica Quim) for 1 min and plaque was scored on each of the 10 test teeth on the buccal and lingual/ palatal surfaces (i.e. a total of 20 sites) using Turesky et al.'s [12] modification of the Quigley and Hein plaque index (TQHPI). Scoring was as follows: $0=$ no plaque/debris; 1 = separate flecks of plaque at the cervical margin of the tooth; $2=$ a thin continuous band of plaque $(\leq 1$ $\mathrm{mm}$ ) at the cervical margin; $3=a$ band of plaque wider than $1 \mathrm{~mm}$ but covering $<$ one-third of the crown of the tooth; $4=$ covering $\geq$ one-third but $<$ twothirds of the crown of the tooth; and $5=$ plaque covering $\geq$ two-thirds of the crown of the tooth. 
All plaque scoring was performed by the same examiner (H.A.), who was calibrated for plaque scoring before commencement of the study and was blind to the baseline score and the treatment group assignments. Reproducibility of plaque scoring was $92.4 \%$ when the examiner was re-scored on 7 randomly selected sites.

\section{Toothbrush wear}

Toothbrush wear was assessed by measurement of the brushing surface area. Standardized digital photographs of each toothbrush were obtained and were downloaded onto a computer. The outline of the brushing surface area on each of the bitmapped images was traced and the surface area within the outline was determined using National Institutes of Health imaging software. Reproducibility of the tracing procedure was assessed by preparing 20 tracings of each of 5 brush heads selected randomly and calculating the mean and SD for each brushing surface area.

\section{Analysis}

Plaque scores for buccal, lingual/palatal and total surfaces obtained in each subject were recorded at baseline and following brushing. The differences between pre- and post-brushing scores, expressed as percentage reduction in plaque score, were used for paired $t$-test comparisons. All analyses were performed using SPSS, version 15. Efficacy analysis was based on a 95\% (2-sided) confidence interval (CI) with a 5\% significance level. Correlations between bristle wear of the 3-month-old toothbrushes and plaque removal efficiency for buccal or lingual/palatal surfaces were analysed using Pearson correlation coefficient. The level of significance was considered as $P<0.05$.

\section{Results}

A total of 93 children (all male, aged 7-9 years) completed the study. Using paired $t$-test, the difference between pre-brushing plaque scores for new and worn toothbrushes were not statistically different $(P=0.28)$. The percentage reduction in plaque score achieved when brushing with the new toothbrushes did not differ significantly from those achieved with the 3-month-old toothbrushes for any of the tooth surfaces (Table 1). Both the new and 3-monthold toothbrushes reduced plaque scores significantly more on buccal surfaces than on lingual/palatal surfaces. For new toothbrushes the scores were $63.7 \%$ versus $50.3 \%$; ( $13.4 \%$ difference; 95\% CI: $10.3 \%-16.5 \%, P<0.001)$; for 3-month-old toothbrushes scores were $63.1 \%$ versus $49.1 \%$ ( $14.1 \%$ difference; $95 \%$ CI: $11.3 \%-16.9 \%, P<0.001)$.

The 3-month-old toothbrushes exhibited increased brushing surface areas ranging from $0.03 \%$ to $90.8 \%$. The mean increase in the brushing surface areas of the worn toothbrushes was 21.7 (SD 14.8). The coefficient of variation for the tracing procedure was $2.8 \%$.

The effect of toothbrush wear on plaque removal was investigated by assessing percentage plaque score reductions achieved with toothbrushes exhibiting varying degrees of wear in comparison with the plaque score reductions achieved by the same patients using new toothbrushes. No significant differences in percentage plaque score reductions were found between new toothbrushes and 3-month old toothbrushes exhibiting various degrees of wear (Table 2).

Pearson correlation tests showed plaque removal efficiency of the 3-month-old toothbrushes did not decrease with increasing bristle wear

\begin{tabular}{|c|c|c|c|c|c|c|}
\hline \multirow[t]{3}{*}{ Variable } & \multicolumn{4}{|c|}{ Plaque score } & \multirow{3}{*}{$\begin{array}{c}\text { Difference in \% plaque score } \\
\text { reduction }(95 \% \mathrm{Cl}), \\
\text { new versus old brush }\end{array}$} & \multirow[t]{3}{*}{$P$-value } \\
\hline & \multicolumn{2}{|c|}{ New brush } & \multicolumn{2}{|c|}{ Worn brush } & & \\
\hline & Mean & SD & Mean & SD & & \\
\hline \multicolumn{7}{|l|}{ Buccal surfaces } \\
\hline Pre-brushing & 29.7 & 4.6 & 29.4 & 4.4 & & \\
\hline Post-brushing & 10.6 & 3.0 & 10.8 & 2.9 & & \\
\hline$\%$ reduction & 63.7 & 10.4 & 63.1 & 8.9 & 0.6 (-0.9 to 2.1$)$ & 0.44 \\
\hline \multicolumn{7}{|c|}{ Lingual/palatal surfaces } \\
\hline Pre-brushing & 27.5 & 4.8 & 27.1 & 4.5 & & \\
\hline Post-brushing & 13.7 & 3.5 & 13.8 & 3.4 & & \\
\hline$\%$ reduction & 50.3 & 9.2 & 49.1 & 9.7 & $1.3(-0.1$ to 2.7$)$ & 0.08 \\
\hline \multicolumn{7}{|l|}{ All surfaces } \\
\hline Pre-brushing & 28.6 & 4.8 & 28.2 & 4.6 & & \\
\hline Post-brushing & 12.1 & 3.6 & 12.3 & 3.5 & & \\
\hline$\%$ reduction & 57.0 & 11.9 & 56.1 & 11.7 & $0.9(-0.1$ to 2.0$)$ & 0.08 \\
\hline
\end{tabular}

$S D=$ standard deviation $; C I=$ confidence interval . 


\begin{tabular}{|c|c|c|c|c|c|c|c|}
\hline \multirow[t]{3}{*}{ BSA increase (\%) } & \multirow[t]{3}{*}{ No. } & \multicolumn{4}{|c|}{ Plaque score } & \multirow{3}{*}{$\begin{array}{l}\text { Difference in mean scores } \\
(95 \% \mathrm{Cl}), \text { new versus old } \\
\text { brush }\end{array}$} & \multirow[t]{3}{*}{$P$-value } \\
\hline & & \multicolumn{2}{|c|}{ New brush } & \multicolumn{2}{|c|}{ Worn brush } & & \\
\hline & & Mean & SD & Mean & SD & & \\
\hline $0.03-9.9$ & 21 & 57.7 & 11.0 & 56.2 & 12.0 & 1.5 (-0.1 to 3.0$)$ & 0.06 \\
\hline 10-39.9 & 65 & 56.1 & 11.5 & 56.5 & 11.8 & 0.3 (-0.9 to 1.6) & 0.61 \\
\hline $40-90.8$ & 7 & 58.2 & 13.8 & 57.6 & 12.2 & 0.6 (-1.9 to 3.1$)$ & 0.61 \\
\hline
\end{tabular}

$B S A=$ brushing surface areas; $S D=$ standard deviation; $C I=$ confidence interval

for either buccal surfaces $(r=0.162$, $P=0.122)$ or lingual $/$ palatal surfaces $(r=-0.067, P=0.525)$ (Figure 1).

\section{Discussion}

Regular removal of plaque from all tooth surfaces is paramount for the maintenance of healthy oral tissue, and the manual toothbrush is the principal device for home care plaque removal [13]. Once bristles become worn, it has been assumed on the basis of in vitro and in vivo studies that toothbrushes have a reduced capacity to remove plaque and require replacement $[6,7]$. However, evidence from more recent studies indicates that bristle wear of toothbrush may not impede the effectiveness of plaque removal [14]. Given the economic situation in underdeveloped countries, clinical studies are crucial for establishing the relative merits of replacing toothbrushes in children.

We concluded that 3-month-old brush heads were as effective as new brush heads in the hands of schoolchildren even when the toothbrushes displayed marked wear. This crossover study consisted of $48 \mathrm{~h}$ of plaque accumulation after which the participants brushed for 1 minute either with new or worn toothbrushes. This design facilitated the exclusion of patient-related factors such as brushing force and style, and allowed a reliable comparison of the plaque-removing capacity of new versus worn brushes in the same patient. Typically, $48 \mathrm{~h}$ of oral hygiene abstinence are used to test the efficacy of toothbrushes $[14,15]$. Biofilm thickness increases only slightly between 24 and 48 h of plaque accumulation, but the structure changes to dense [16]. During each visit, participants used their assigned brushes for 1 min, which broadly represents the average brushing time in the general population [17].

A key factor in assessing the relative plaque removal performance of different toothbrushes is the ability to quantify the amount and distribution of plaque on tooth surfaces before and after brushing [13]. In this study, the plaque removal effectiveness of toothbrushes was expressed as mean percentage plaque score reductions according to the TQHPI. This index is recognized as a reliable index for measuring plaque removal after toothbrushing [18]. Our findings showed a wide variation in the brushing surface areas of the 3-month old toothbrushes, with surface area increases ranging from $0.3 \%$ to $90.8 \%$. The greater variation in bristle wear that has been identified in previous studies of manual toothbrushes $[10,14]$ may be
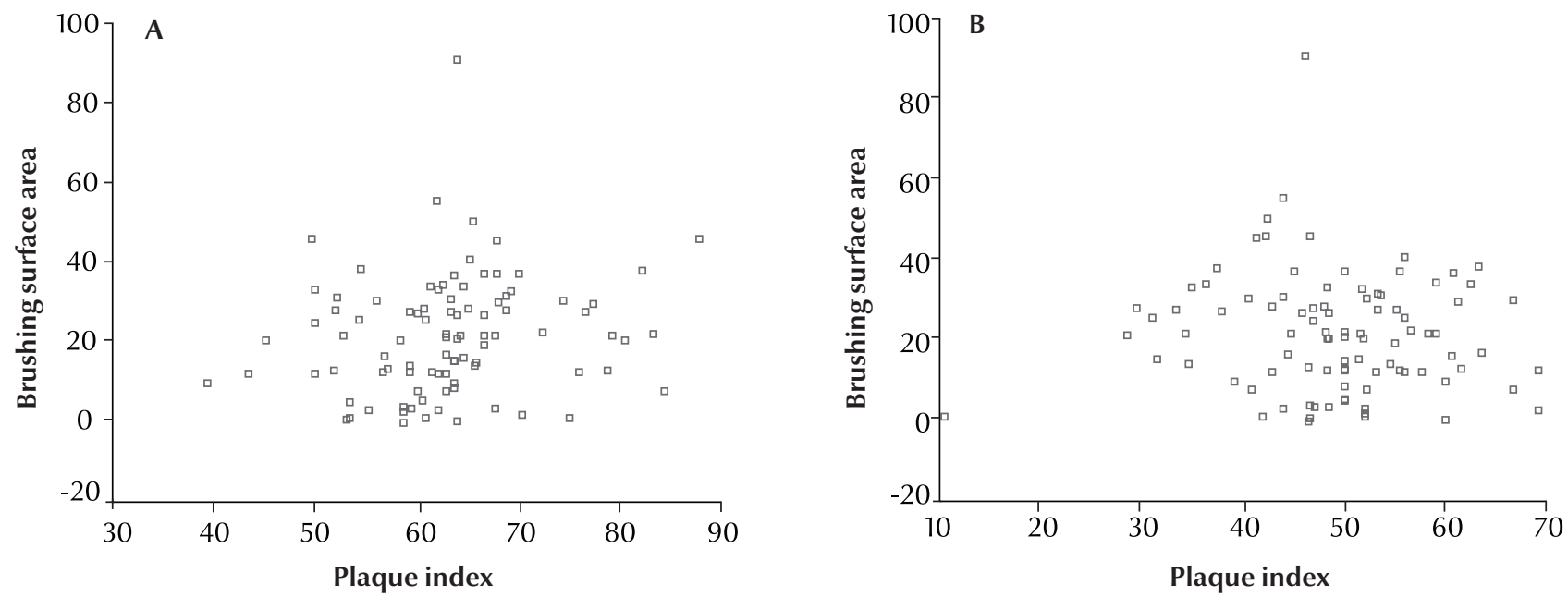

Figure 1 Percentage plaque score reductions achieved with 3-month-old toothbrushes in relation to the increase in the brushing surface areas of each toothbrush ( $n=93$ children $)(A=$ buccal surfaces; $B=$ lingual/palatal surfaces $)$ 
due to greater toothbrushing forces in adult subjects.

In this study, the grading of brush head wear was objectively assessed by digitally measuring the brushing surface area of the worn heads in a reproducible and accurate manner. It was found that even those brushes exhibiting marked wear were no less effective than new toothbrushes in reducing plaque scores. These results confirm the findings of previous studies reporting that the capacity of 3-month-old brushes to remove plaqueis not related to toothbrush wear $[8,9]$. Sforza et al. reported that plaque scores and gingival indices were no different in university students who changed their toothbrushes monthly compared with those whoused the same brush for the entire 3 months of the study [8]. They confirmed the findings of Daly et al. that increased toothbrush wear was not associated with worsening plaque scores [9]. These observations suggest that plaque control is not dependent only on toothbrush wear and it is rational to suppose that other factors may be influential, such as brushing time or pressure [8].

In contrast, some studies demonstrated that worn toothbrushes have less capacity to remove plaque compared with those less worn $[6,7,19]$. Warren et al. subjected new toothbrushes to a laboratory wear machine to simulate 3 months of clinical toothbrush use [6]. They found that a worn toothbrush was less effective than a new toothbrush for plaque removal and control of gingivitis. However, artificially worn toothbrushes do not model natural wear well and are therefore not necessarily clinically relevant tools in studies on plaque removal efficacy [11]. Conforti et al. instructed subjects to use manual or powered toothbrushes twice per day for 3 months and found that worn brushes were less efficient for plaque removal than new brushes [7]. They recommended that toothbrushes be replaced regularly before bristle wear becomes excessive. However, they used adult subjects, and the results may not apply to children. In the only other study investigating the effect of toothbrush age and wear on plaque removal in children, van Palenstein Helderman et al. instructed 7 - and 8-year-old children to brush daily after lunch in a school-based toothbrushing programme [11]. After 14 months the effect of toothbrush wear on plaque removal was investigated. However, they could not assess toothbrush wear, since no clear variation was apparent in bristle-matting of old toothbrushes. Encouraged by such results, we conducted a comparative clinical study to verify whether those results would hold for children in an age group similar to that at which many prevention programmes are directed.

It has been shown that young children have manual dexterity difficulties in brushing lingual surfaces of teeth [20]. This was confirmed in the present study, with the higher mean percentage plaque removal achieved at the buccal sites and the lower from the lingual sites regardless of whether a new or a 3-month-old toothbrush was used.
The question remains about the level of plaque removal that should be reached in respect to prevention of caries and gingivitis within 1 session of oral hygiene [15]. Nevertheless the level of plaque removal presented by both new and old toothbrushes in this study seems to be inadequate from the clinical point of view. It is possible that the low percentage plaque score reductions were influenced by subjects brushing without a mirror. However, it must be emphasized that this study was conducted with 7-9-year-old children, who may not have adequate toothbrushing technique [21,22].

The results from this study provide further data in support of the hypothesis that a worn toothbrush is no less efficient with respect to plaque removal than a new brush. These results are important from a public health point of view, especially in developing countries, where the dissemination of preventive techniques that are low cost is fundamental.

Considering the paucity of studies on this issue, further investigations should be performed to establish the appropriate time interval before needing to discard children's toothbrushes.

\section{Acknowledgements}

This paper has been entirely drawn up from an undergraduate thesis which was successfully completed by $\mathrm{Dr} \mathrm{H}$. Abbasi under the supervision of Dr B. Malekafzali.

\section{References}

1. Löe H. Oral hygiene in the prevention of caries and periodontal disease. International Dental Journal, 2000, 50:129-139.

2. Axelsson P, Nystrom B, Lindhe J. The long-term effect of a plaque control program on tooth mortality, caries and periodontal disease in adults. Results after 30 years of maintenance. Journal of Clinical Periodontology, 2000, 31:749-757.

3. Haffajee AD et al. Efficacy of manual and powered toothbrushes (II). Effect on microbiological parameters. Journal of Clinical Periodontology, 2001, 28:947-954.
4. Das UM, Singhal P. Tooth brushing skills for the children aged 3-11 years. Journal of the Indian Society of Pedodontics and Preventive Dentistry, 2009, 27:104-107.

5. ADA Division of Communications. For the dental patient. Toothbrush care, cleaning and replacement. Journal of the American Dental Association, 2006, 137:415.

6. Warren PR et al. A clinical investigation into the effect of toothbrush wear on efficacy. Journal of Clinical Dentistry, 2002, 13:119-124. 
7. Conforti NJ et al. An investigation into the effect of three months' clinical wear on toothbrush efficacy: results from two independent studies. Journal of Clinical Dentistry, 2003, 14:29-33.

8. Sforza NM et al. Plaque removal by worn toothbrush. Journal of Clinical Periodontology, 2000, 27:212-216.

9. Daly CG, Chapple CC, Cameron AC. Effect of toothbrush wear on plaque control. Journal of Clinical Periodontology, 1996, 23:45-49.

10. Tan E, Daly C. Comparison of new and 3-month-old toothbrushes in plaque removal. Journal of Clinical Periodontology, 2002, 29:645-650.

11. van Palenstein Helderman WH et al. Plaque removal by young children using old and new toothbrushes. Journal of Dental Research, 2006, 85:1138-1142.

12. Turesky S, Gilmore ND, Glickman I. Reduced plaque formation by the chloromethyl analogue of victamine C. Journal of Periodontology, 1970, 41:41-43.

13. Cugini M, Thompson M, Warren PR. Correlations between two plaque indices in assessment of toothbrush effectiveness. Journal of Contemporary Dental Practice, 2006, 7:1-9.

14. Hogan LME, Daly CG, Curtis BH. Comparison of new and 3-month-old brush heads in the removal of plaque using a powered toothbrush. Journal of Clinical Periodontology, 2007, 34:130-136.
15. Pelka AK et al. Professional brushing study comparing the effectiveness of sonic brush heads with manual toothbrushes: a single blinded, randomized clinical trial. Clinical Oral Investigations, 2010, doi:10.1007/s00784-010-0411-0 [epub ahead of print].

16. Zaura-Arite E, van Marle J, ten Cate JM. Conofocal microscopy study of undisturbed and chlorhexidine-treated dental biofilm. Journal of Dental Research, 2001, 80:1436-1440.

17. Creeth JE et al. The effect of brushing time and dentifrice on dental plaque removal in vivo. Journal of Dental Hygiene, 2009, 83:111-116.

18. Robinson PG et al. Manual versus powered toothbrushing for oral health. Cochrane Database of Systematic Reviews, 2005, 18:CD002281.

19. Muller-Bolla M et al. Manual toothbrush wear and consequences on plaque removal. Journal of Clinical Dentistry, 2007, 18:73-78.

20. Livny A et al. Oral health promotion for schoolchildren-evaluation of a pragmatic approach with emphasis on improving brushing skills. BMC Oral Health, 2008, 8:4.

21. Sundell SO, Klein H. Toothbrushing behavior in children: a study of pressure and stroke frequency. Pediatric Dentistry, 1982, 4:225-227.

22. Unkel $\mathrm{JH}$ et al. Toothbrushing ability is related to age in children. ASDC Journal of Dentistry for Children, 1995, 62:346-348.

\section{Manual for the health care of children in humanitarian emergencies}

The objective of the Manual for the health care of children in humanitarian emergencies is to provide comprehensive guidance on child care in emergencies. Existing guidelines, such as IMCI, assume a functioning health system that facilitates the referral of children, which may not be available in emergency situations. So this manual also includes the initial management of severe conditions. It was also realized that existing manuals do not cover injuries, burns, neonatal illness, psychosocial problems etc, which are considered of high priority in emergency settings. These are addressed as well as issues on mental health, psychosocial support and common preventive interventions such as immunization.

Each chapter summarizes the main ways of diagnosis, treatment and prevention using flow charts. The flow charts are arranged in such a way that they can be enlarged for use as job aids/wall charts, or for modular training at convenient times on the management of each condition.

The manual can be accessed at:

http://www.who.int/child_adolescent_health/documents/9789241596879/en/index.html 